\title{
EVIDENCE BRIEF SCRATCH CARD NEAR-MISS OUTCOMES
}

Scratch card near-
misses impact
gamblers
significantly -
despite being a
monetary loss.

Scratch card near-

misses impact

gamblers

significantly -

monetary loss.

\author{
EXECUTIVE SUMMARY \\ Scratch card games are an accessible and popular form \\ of gambling in many jurisdictions. Recent research has \\ started to examine features of scratch card games and \\ their impact on gamblers. One such feature is the near- \\ miss: an outcome that falls just short of a jackpot win. \\ Despite being a monetary loss, scratch card near-misses \\ impact gamblers significantly.
}

This evidence brief examines research about scratch card near-miss outcomes and their impact on gamblers (both physiologically and psychologically). Connections between scratch cards and gambling harm are explored. A jurisdictional scan shows the regulation of this game feature in various markets. Limitations of the current evidence and suggestions for future research are included.

Empirical evidence for near-miss effects in scratch cards is strong, but still in its infancy. Additional research will further our understanding of these game features, and help gauge the risk they pose. This will enable effective policy and regulatory controls to mitigate gambling harm. 


\section{EVIDENCE REVIEW}

\section{INTRODUCTION}

The concept of a near-miss (sometimes called a "near-win") has existed for several decades, usually related to electronic gaming machines or slot machines. However, near-miss outcomes exist in many different types of gambling, including lottery games and scratch cards (also referred to as "instant lottery games"). ${ }^{1,2}$ Near-misses are defined as an outcome that comes close to a win, but falls just short, typically by collecting two of the three required symbols to win a prize. ${ }^{3}$ In a classic slot machine near-miss, the gambler lands two jackpot symbols on a slot machine payline, but narrowly misses the third.

Several authors have researched the impact of near-misses on gamblers over the years, with the focus predominantly on slot machine games. A systematic review identified 51 experimental peer-reviewed studies examining near-miss outcomes in slot machines. ${ }^{4}$ This review identified studies using human participants between 1991 and 2015, conducted in eight nations. There have been more studies since that date, as well as studies examining nearmiss outcomes in other forms of gambling. With the rising popularity of scratch card games in many jurisdictions, this form of gambling has recently been a topic of increased research, especially the presence of near-miss outcomes in these games.

\section{IMPACTS ON THE GAMBLER}

Studies have found that gamblers find slot machine near-misses paradoxically motivating yet unpleasant. ${ }^{5}$ In scratch card games, when compared to a regular, full loss, gamblers typically report greater levels of frustration, negative emotion, disappointment, and urge to continue gambling. ${ }^{6}$

In addition to these effects, near-misses have been shown to influence how hard players press a slot-machine stop button ${ }^{7}$ and can also increase motivation in subsequent, unrelated tasks. ${ }^{8}$ In slot machine games, near-misses lead to players persisting in play ${ }^{9,10}$ and cause gamblers to move onto their next spin more quickly. ${ }^{11}$

Physiological arousal, considered to be the main reinforcer of gambling behaviour, ${ }^{12}$ is also increased when near-miss outcomes are encountered in both slot machines ${ }^{13}$ and scratch cards. ${ }^{14}$ For example, skin-conductance levels are typically found to be equally high or higher for near-misses compared to wins in scratch cards. ${ }^{6}, 14$ Studies have also reported heart rate increases in response to near-miss outcomes compared to full miss outcomes in scratch cards. ${ }^{6}$ Further, slot machine near-miss outcomes have been shown to be associated with increased activity in the brain's reward areas. ${ }^{15}$ Crucially, near-miss outcomes are capable of these effects even though they are monetary losses and do not result in an objective, 
monetary gain for the gambler. These findings may be seen as evidence for the reinforcement for monetary losses during gambling - a difficult proposition from a responsible gambling perspective.

Although scratch card near-misses increase the urge to gamble ${ }^{6,16}$ and physiological arousal, 6,14 the relationship between outcome-induced urge and further gambling behaviour still needs to be fully explored. In a study examining the impact of near-miss outcomes on behaviour, experiencing a near-miss rather than a full miss did not result in participants purchasing more scratch cards. ${ }^{16}$ Despite this finding, near-miss outcomes did lead to significantly greater urge to gamble than full misses. Additionally, in this study there was a positive correlation between urge following the near-miss and purchasing additional cards only for the near-miss group; no such connection was seen for the loss group. This suggests that after a near-miss, the urge that a gambler experiences is related to whether or not they purchase additional scratch cards.

\section{CONNECTIONS TO GAMBLING-RELATED HARM}

The GamGard tool, developed by academics and used by 31 companies and regulators in 16 nations to assess risks within gambling products, includes near-misses as a risk factor. ${ }^{17}$ The maximum score (representing highest risk) for near-misses is 4 towards a maximum risk score of 100 . This suggests that other game features, such as event frequency and continuity of play potential have been assessed as being riskier. However, it is important to note that the effects of structural characteristics in various gambling forms do not happen in isolation; near-misses interact with other structural characteristics that are present in specific game types, and therefore not all forms of lottery have the same risk profiles.

Scratch cards have a much faster event frequency than traditional, draw-based lottery games, as the prizes can be uncovered and redeemed instantly, instead of having to wait for a weekly draw. ${ }^{2}$ Further, scratch cards offer the opportunity for continual play, as unlike a traditional lottery draw, there is no limit to purchasing additional cards. Therefore, the presence of nearmiss outcomes, in addition to these known structural risks, may be of special concern for mitigating gambling harm specific to scratch card lottery products.

A small number of studies have examined scratch card-related gambling harm. Overall, estimates suggest that the number of people experiencing scratch card addiction are low. ${ }^{18,} 19$ However, case reports of pathological scratch card gambling have been published, ${ }^{20}$ as have reports of scratch card gambling harm in youth populations. ${ }^{21}$ In a Canadian analysis that controlled for demographic factors and the frequency of traditional draw-based lottery play, frequency of scratch card play predicted additional significant variance in problem gambling severity. ${ }^{22}$ Further, longitudinal data suggests that the frequency of scratch card play may predict problem gambling over a 5-year timespan. ${ }^{23}$ An examination of problematic gambling in Massachusetts found that of those problem gamblers who had a problematic form of 
gambling, instant lottery games were the most commonly reported game type. ${ }^{24}$ Finally, reliable associations between scratch card frequency and problem gambling severity have been reported in online samples. ${ }^{25}$

Although near-miss outcomes in scratch card games have been shown to reliably increase the urge to continue gambling, and have been found to be associated with gambling harm in many jurisdictions, virtually no empirical research has examined the impact of scratch card nearmisses on players who are experiencing gambling harm. So far, laboratory-based scratch card studies have only used samples of undergraduate students, who despite having experience with scratch cards, typically report lower levels of problem gambling severity than the general population. Therefore, future research would benefit greatly from using samples of community gamblers experiencing varying levels of gambling harm to determine the effects of near-miss outcomes on their cognitions and behaviours.

\section{LIMITATIONS}

There are some key limitations to the research that may impact the extent to which these findings can be applied. Many near-miss studies examined these outcomes in slot machines, which are quite structurally different from scratch card games. Further, nearly all of the reviewed research consisted of studies conducted in a laboratory setting with reasonably small sample sizes, and sometimes with student participants that may not gamble as often as the general population. Finally, most laboratory-based gambling studies require participants to gamble with money that was provided by researchers and cannot likely result in a realisticallysized jackpot prize. However, near-miss effects have been consistently replicated across studies. So it is possible that these limitations suggest that the current results are merely an underestimate of true near-miss effects in the real world. Future research should try to address these limitations to derive a more comprehensive understanding of scratch card gambling. 


\section{JURISDICTIONAL SCAN}

An analysis of scratch card game design found evidence of manufactured near-miss outcomes in a popular scratch card game available for sale in Ontario, Canada. ${ }^{26}$ This was accomplished by over-representing the top prize symbol in pairs, in a game in which three top prize symbols are required to win. This technique creates many more near-miss outcomes than would occur on a card with an equal distribution of prize symbols. Some jurisdictions have regulatory controls in place to limit the number of near-miss outcomes expressed in nonlottery forms of gambling, ${ }^{27}$ due to the misleading information about winning they portray to the gambler. It is unknown if regulatory controls to address near-miss outcomes in scratch card games exist.

Various jurisdictions were examined with regards to regulations concerning near-miss outcomes in scratch cards. Overall, no jurisdiction used regulatory controls for scratch card near-misses specifically. However, some regulatory practices specific to game design or nearmisses generally were present, and these points of interest are included in the table below.

\section{RESULTS}

\begin{tabular}{|c|c|c|}
\hline Jurisdiction & $\begin{array}{l}\text { Scratch Card Near- } \\
\text { Miss Regulations }\end{array}$ & Other Points of Interest \\
\hline $\begin{array}{l}\text { Australia } \\
\text { (New South Wales) }\end{array}$ & No & $\begin{array}{l}\text { - In the Public Lotteries Regulation, }{ }^{28} \text { instant } \\
\text { lottery tickets (“scratchies") are exempt from a } \\
\text { subclause specifying that lottery products must } \\
\text { include gambling help resources (Clause 12, } \\
\text { Subclause 2). }\end{array}$ \\
\hline $\begin{array}{l}\text { Australia } \\
\text { (Queensland) }\end{array}$ & No & $\begin{array}{l}\text { - In the Lotteries Rule, }{ }^{29} \text { the Minister can } \\
\text { approve "the layout and wording of tickets" ( } p \text {. } \\
41 \text { ), although it is not clear if this includes the } \\
\text { layout and wording of specific game outcomes. }\end{array}$ \\
\hline $\begin{array}{l}\text { Canada } \\
\text { (Ontario) }\end{array}$ & No & $\begin{array}{l}\text { - In the Registrar's Standards for Gaming: } \\
\text { Lottery Sector, }{ }^{30} \text { it is stated that "Game } \\
\text { designs and features shall be clear and shall } \\
\text { not mislead the player" (p. 24). } \\
\text { - Although the Standards state that a near-miss } \\
\text { cannot be substituted for a regular loss } \\
\text { through a "variable secondary decision" (p. } \\
\text { 24), this type of on-line substitution is } \\
\text { impossible in scratch cards and render this } \\
\text { guideline not applicable. }\end{array}$ \\
\hline
\end{tabular}




\begin{tabular}{|c|c|c|}
\hline & & $\begin{array}{l}\text { For games involving reels (not applicable to } \\
\text { scratch cards), the Standards dictate specific } \\
\text { limits on how often a jackpot symbol can occur } \\
\text { adjacent the payline for each time they occur } \\
\text { on the payline (p. 25). }\end{array}$ \\
\hline $\begin{array}{l}\text { Canada } \\
\text { (British Columbia) }\end{array}$ & No & $\begin{array}{l}\text { Technical Gaming Standards for Non- } \\
\text { Electronic Scratch and Win Tickets }{ }^{31} \text { include } \\
\text { detailed descriptions of the structure of various } \\
\text { scratch card game designs, but place no } \\
\text { restrictions on the arrangement of symbols } \\
\text { within these games. }\end{array}$ \\
\hline Estonia & No & $\begin{array}{l}\text { - Gambling operators are required to "ensure } \\
\text { that a clear warning is presented to a player } \\
\text { regarding the addictive nature of gambling and } \\
\text { that a reference is made to the contact details } \\
\text { of organizations that assist gambling addicts" } \\
\text { (Chapter } 3 \S 33.5 \text { ). }{ }^{32}\end{array}$ \\
\hline France & No & - $\mathrm{N} / \mathrm{A}$ \\
\hline Netherlands & No & $\begin{array}{l}\text { Duty of Care }{ }^{33} \text { policies dictate that the "license } \\
\text { holder enables consumers to make an } \\
\text { informed choice when participating" (p. 6) } \\
\text { including informing them about "the } \\
\text { characteristics of the game of chance" (p. 6). }\end{array}$ \\
\hline Sweden & No & $\begin{array}{l}\text { - In the Gambling Act, }{ }^{34} \text { the design of games is } \\
\text { restricted such that "[i]t is not permitted to } \\
\text { specifically design or program a game so that } \\
\text { players are given the impression of being close } \\
\text { to winning when such is not the case" (Chapter } \\
14 \S 5 \text { ). }\end{array}$ \\
\hline United Kingdom & No & $\begin{array}{l}\text { - In the licensing of scratch card games to the } \\
\text { gambling operator, it is specified that scratch } \\
\text { card games will not be "designed in a way that } \\
\text { misrepresents the chance of winning a prize" } \\
\text { or "in a way that encourages excessive or } \\
\text { reckless playing" (Issue } 2 \text {, Version } 9 \text {, Schedule } \\
4 \text { ). }{ }^{35} \\
\text { - Manufactured near-misses are prohibited in } \\
\text { remote gambling and software technical } \\
\text { standards (which apply to online products, }\end{array}$ \\
\hline
\end{tabular}




\begin{tabular}{|c|c|c|}
\hline & & $\begin{array}{l}\text { other than those licensed by the National } \\
\text { Lottery etc Act, 1993)' } \\
\text { - ) specify that "[g]ame designs or features that } \\
\text { may reasonably be expected to mislead the } \\
\text { customer about the likelihood of particular } \\
\text { results occurring are not permitted, including } \\
\text { substituting losing events with near-miss losing } \\
\text { events" (RTS requirement 7C, p. 18). }{ }^{27}\end{array}$ \\
\hline $\begin{array}{l}\text { United States } \\
\text { (New Jersey) }\end{array}$ & No & - $N / A$ \\
\hline
\end{tabular}

\section{CONCLUSION}

The research findings reviewed above suggest that near-miss outcomes impact gamblers both physiologically and psychologically. They are frustrating, disappointing, yet highly motivating and arousing outcomes that happen often in this type of gambling. Near-misses may be considered a potentially influential risk factor in the design of scratch card games - a form of gambling that is popular, highly accessible, and associated with gambling harm.

Despite this, regulatory control of near-miss outcomes in scratch card games is minimal. The review of select jurisdictions revealed regulations of game design that aim to ensure that scratch card games do not "misrepresent[s] the chance of winning a prize", ${ }^{35}$ that lottery game "designs and features shall be clear and shall not mislead the player", ${ }^{30 p .24}$ or that the design of games does not give "the impression of being close to winning when such is not the case". ${ }^{34}$ However, none of these regulations specify limits on, or prohibit the inclusion of, nearmiss outcomes specifically.

Existing evidence suggests that scratch card near-misses impact players, and that their presence is largely an area of limited regulatory control. Investment in research to further our understanding of how these outcomes impact gamblers and how prevalent they are in modern game designs in multiple jurisdictions, will allow for a more sensitive and nuanced approach to their regulation. Addressing near-miss outcomes in all forms of gambling is a necessary step to ensure fair, transparent, and safe gambling practices, as well as to minimize potential gambling harm. 


\section{REFERENCES}

1. Griffiths MD. Scratch-card gambling: a potential addiction? Education and Health. 1995;13(2):17-20.

2. Griffiths MD. Are lottery scratchcards a 'hard' form of gambling? eGambling-The Electronic Journal of Gambling Issues (EJGI). 2002(7).

3. Reid RL. The psychology of the near miss. Journal of Gambling Behavior. 1986;2(1):32-9. 4. Barton KR, Yazdani Y, Ayer N, Kalvapalle S, Brown S, Stapleton J, et al. The effect of losses disguised as wins and near misses in electronic gaming machines: a systematic review. Journal of Gambling Studies. 2017;33(4):1241-60. Plain language summary available at http://www.greo.ca/Modules/EvidenceCentre/Details/a-systematic-review-of-near-missesand-losses-disguised-as-wins

5. Clark L, Liu R, McKavanagh R, Garrett A, Dunn BD, Aitken MRF. Learning and affect following near-miss outcomes in simulated gambling. Journal of Behavioral Decision Making. 2013;26(5):442-50.

6. Stange M, Grau M, Osazuwa S, Graydon C, Dixon MJ. Reinforcing small wins and frustrating near-misses: further investigation into scratch card gambling. Journal of Gambling Studies. 2017;33(1):47-63.

7. Dixon MJ, Larche CJ, Stange M, Graydon C, Fugelsang JA. Near-misses and stop buttons in slot machine play: an investigation of how they affect players, and may foster erroneous cognitions. Journal of Gambling Studies. 2018(34):1. Plain language summary available at http://www.greo.ca/Modules/EvidenceCentre/Details/stop-buttons-in-slot-machine-play-mayfoster-cognitive-biases-about-gambling-skil

8. Wadhwa M, Kim JC. Can a near win kindle motivation? the impact of nearly winning on motivation for unrelated rewards. Psychological Science. 2015;26(6):701-8.

9. Cote D, Caron A, Aubert J, Desrochers V, Ladouceur R. Near wins prolong gambling on a video lottery terminal. Journal of Gambling Studies. 2003;19(4):433-8.

10. Kassinove JI, Schare ML. Effects of the 'near miss' and the 'big win' on persistence at slot machine gambling. Psychology of Addictive Behaviors. 2001;15(2):155-8.

11. Dixon MJ, MacLaren V, Jarick M, Fugelsang JA, Harrigan KA. The frustrating effects of just missing the jackpot: slot machine near-misses trigger large skin conductance responses, but no post-reinforcement pauses. Journal of Gambling Studies. 2013;29(4):661-74.

12. Brown RIF. Arousal and sensation-seeking components in the general explanation of gambling and gambling addictions. International Journal of the Addictions. 1986;21(9-

10):1001-16.

13. Dixon MJ, Harrigan KA, Jarick M, MacLaren V, Fugelsang JA, Sheepy E.

Psychophysiological arousal signatures of near-misses in slot machine play. International Gambling Studies. 2011;11(3):393-407.

14. Stange M, Graydon C, Dixon MJ. "I was that close": investigating players' reactions to losses, wins, and near-misses on scratch cards. Journal of Gambling Studies. 2016;32(1):187203. Plain language summary available at

http://www.greo.ca/Modules/EvidenceCentre/Details/undergraduate-students-rate-scratchcard-near-miss-outcomes-more-frustrating-losing-outcomes

15. Clark L, Lawrence AJ, Astley-Jones F, Gray N. Gambling near-misses enhance motivation to gamble and recruit win-related brain circuitry. Neuron. 2009;61(3):481-90.

16. Stange M, Graydon C, Dixon MJ. Increased urge to gamble following near-miss outcomes may drive purchasing behaviour in scratch card gambling. Journal of Gambling Studies.

2017;33(3):867-79. Plain language summary available at

http://www.greo.ca/Modules/EvidenceCentre/Details/near-misses-in-scratch-card-gamesincrease-young-adults-desire-to-gamble-and-mot

17. GamGuard. Guiding responsible design. 2017. Available from: https://www.gamgard.com/. 18. DeFuentes-Merillas L, Koeter MW, Bethlehem J, Schippers GM, van den Brink W. Are scratchcards addictive? The prevalence of pathological scratchcard gambling among adult scratchcard buyers in the Netherlands. Addiction. 2003;98(6):725-31.

19. Hendriks VM, Meerkerk GJ, Van Oers HA, Garretsen HF. The Dutch instant lottery: prevalence and correlates of at-risk playing. Addiction. 1997;92(3):335-46. 
20. Raposo-Lima C, Castro L, Sousa N, Morgado P. SCRATCH THAT! - two case reports of scratch-card gambling disorder. Addictive Behaviors. 2015;45:30-3.

21. Wood RT, Griffiths MD. The acquisition, development and maintenance of lottery and scratchcard gambling in adolescence. Journal of Adolescence. 1998;21(3):265-73.

22. Short MM, Penney AM, Mazmanian D, Jamieson J. Lottery ticket and instant win ticket gambling: exploring the distinctions. Journal of Gambling Issues. 2015(30):6-21. Plain language summary available at http://www.greo.ca/Modules/EvidenceCentre/Details/differences-between-lottery-ticket-andinstant-win-ticket-gamblers

23. Williams RJH, Robert, Schopflocher D, West B, McLaughlin P, White N, King K, et al. Quinte longitudinal study of gambling and problem gambling. Guelph: Canada; 2015.

Available from: http://www.greo.ca/Modules/EvidenceCentre/Details/quinte-longitudinal-studygambling-and-problem-gambling-1.

24. Mazar A, Williams RJ, Stanek EJ, 3rd, Zorn M, Volberg RA. The importance of friends and family to recreational gambling, at-risk gambling, and problem gambling. BMC Public Health. 2018;18(1):1080. Plain language summary available at

http://www.greo.ca/Modules/EvidenceCentre/Details/gamblers-with-a-lower-portion-of-friendsand-family-who-gamble-may-have-a-lower-r

25. Stange M, Walker AC, Koehler DJ, Fugelsang JA, Dixon MJ. Exploring relationships

between problem gambling, scratch card gambling, and individual differences in thinking style. Journal of Behavioral Addictions. 2018;7(4):1022-9.

26. Stange M, Brown DG, Harrigan K, Dixon M. Built-in bad luck: evidence of near-miss outcomes by design in scratch cards. Journal of Gambling Issues. 2017(36):51-64. Plain language summary available at http://www.greo.ca/Modules/EvidenceCentre/Details/scratchcard-games-are-designed-to-include-more-near-miss-outcomes

27. Gambling Commission. Remote gambling and software technical standards. 2017. Available from: https://www.gamblingcommission.gov.uk/pdf/Remote-gambling-and-softwaretechnical-standards.pdf.

28. New South Wales Government. Public Lotteries Regulation 2016. 2016. Available from: https://www.legislation.nsw.gov.au/\#/view/regulation/2016/519/whole.

29. Queensland Office of Liquor and Gaming Regulation. Lotteries Rule 2010. 2018. Available from: https://www.publications.qld.gov.au/dataset/gaming-rules/resource/74b51729-5b0448ad-9968-a74d42bddecb.

30. Alcohol and Gaming Commission of Ontario. Registrar's Standards for Gaming: Lottery Sector. 2017. Available from: https://www.agco.ca/sites/default/files/lottery standards apr2017 en.pdf.

31. Ministry of Public Safety and Solicitor General GPaEB. Technical Gaming Standards for Non-Electronic Scratch and Win Tickets. 2008. Available from:

https://www2.gov.bc.ca/assets/gov/sports-recreation-arts-and-culture/gambling/gambling-inbc/stds-tech-gaming-tgsne2.pdf.

32. Riigikogu. Gambling Act. 2008. Available from:

https://www.riigiteataja.ee/en/eli/515012016007/consolide.

33. De Kansspelautoriteit. Duty of Care Guideline. 2019. Available from:

https://kansspelautoriteit.nl/organisatie/doelstellingen/.

34. Ministry of Finance (Finansdepartementet). Gambling Act (2018:1138). 2018. Available

from: http://www.spelinspektionen.se/globalassets/dokument/engelsk/oversatt-

spellagen/english-spellagen-sfs-201 1138.pdf.

35. Gambling Commission. Scratch card games. 2019. Available from:

https://www.gamblingcommission.gov.uk/PDF/NL-licences/Scratchcard-games-licence.pdf. 